\title{
Health-seeking behavior of rural agricultural workers: A community-based cross-sectional study
}

\section{Rajesh R. Kulkarni, Shivaswamy MS, Mahesh D. Mallapur \\ Department of Community Medicine, Jawaharlal Nehru Medical College, Nehru Nagar, \\ Belgaum, Karnataka, India}

Address for the Correspondence:

Dr. Rajesh R. Kulkarni, Department of Community Medicine, Jawaharlal Nehru Medical College, Nehru Nagar, Belgaum - 590 010, Karnataka, India. E-mail: rajesh2kulkarni@gmail.com

\begin{tabular}{|l|}
\hline Access this article online \\
\hline Website: www.jmedph.org \\
\hline DOI: 10.4103/2230-8598.109318 \\
\hline Quick response code: \\
\hline
\end{tabular}

Context: Majority of the Indian population lives in rural area, where the main occupation is agriculture. In developing countries, agriculture workers have multitude of health problems, whereas they do not have access to the adequate health care facilities. Aims: The present study was aimed to know the health-seeking behavior of agricultural workers. Settings and Design: This cross-sectional study was done from January 2009 to December 2009 in a rural area of Bhutaramanahatti sub-center (Vantamuri PHC), Belgaum District. Materials and Methods: A total of 400 agricultural workers of age 16-60 years were interviewed in their households/ fields. Data were acquired on a predesigned and pretested questionnaire. Statistical Analysis Used: Percentages and Chi-square test. Results: Among the study participants $55.75 \%$ were males and $44.25 \%$ were females, with a male to female ratio of $1.25: 1$. Most of the agricultural workers $(89.5 \%)$ were Hindus, $10.5 \%$ were Muslims, and $47 \%$ were illiterates, whereas $38 \%$ had passed first to fifth grades, $14.5 \%$ had passed sixth to tenth grades, and $0.5 \%$ had attended tenth plus. Of the 400 subjects, $295(73.75 \%)$ belonged to Class $V$ socioeconomic status. Overall, $48.75 \%$ opted government doctors and $28 \%$ opted private doctors as the first priority health care providers for their illness. $37.75 \%$ preferred private or AYUSH practitioners and $18.25 \%$ opted government doctors in case illness was not cured or they were not satisfied with the treatment given by the first health care provider. Conclusions: The present study reveals that most of the agricultural workers depended on government doctor for their illness. In order to overcome the situation, special health check-up camps need to be conducted with emphasis on improvement of health.

Key words: Agricultural workers, health-seeking behavior, occupational health

\section{INTRODUCTION}

The literature linking health to labor productivity is built on the concepts of household production theory developed by Becker. In Becker's framework, households are treated also as producers of "commodities" instead of solely consumers of goods and services. This framework was extended by Grossman to analyze the demand for health. In Grossman's model, health is viewed as a durable capital stock that yields an output of healthy time. ${ }^{[1]}$

India lives in its 600,000 villages. Nearly $72 \%$ of the Indian community lives in rural area, where their main occupation is agriculture. Indian agriculture accounts for $25 \%$ of total gross domestic product (GDP) on which $75 \%$ of country's population depends on. Agricultural workers do not have trade unions and have no access to occupational health services. ${ }^{[2]}$ Occupational health in the agricultural sector is a new concept.

These agricultural workers have a multitude of health problems, a fact which is often forgotten because of misconception that occupational health is mainly concerned with industry and industrialized countries. These health problems of workers in agriculture may be accidents (machine injuries, snake and insect bites), toxic hazards (chemical exposures and insecticide poisoning), physical hazards (extreme conditions, solar radiation), and respiratory problems (farmer's lung, occupational asthma). ${ }^{[3]}$

The lack of coordination of policy making between agriculture and health undermines efforts to overcome ill health among the rural poor and gives short shrift to agriculture's role in alleviating 
many of the world's most serious health problems. ${ }^{[4]}$ Health-seeking behavior in terms of illness behavior refers to those activities undertaken by individuals in response to symptom experience. Health-seeking behavior is influenced by a large number of factors apart from knowledge and awareness. This behavior among different populations, particularly in the rural communities, is a complex outcome of many factors operating at individual, family, and community levels, including their bio-social profile, their past experiences with the health services, influences at the community level, availability of alternative health care providers including indigenous practitioners, and last but not the least, their perceptions regarding efficiency and quality of the services. Belief systems prevalent in the communities, that is, how people conceptualize the etiology of health problems and how symptoms are perceived are an important factor in deciding the first step of treatment seeking. ${ }^{[5]}$

Health status in India is remarkable for its myriad contradictions, and where the health situation in some states compares with the best of developing countries, the majority is bracketed with worst in the world. Health system in our country is bogged down with a number of chronic maladies like inappropriate budgetary allocation and a "top-down" hierarchy with multiple levels of operation which have led to compromise in effectiveness and quality of the services. Although considerable progress has definitely been made in the last few decades for expansion of the public health infrastructure, the mere existence or increasing the availability of services does not increase their utilization. ${ }^{[6]}$

Few studies have reported about health-seeking behaviors of agricultural workers toward their illness. Hence, the present study was undertaken to explore health-seeking behavior among the agricultural workers residing in rural area.

\section{MATERIALS AND METHODS}

\section{Study design, period, and area}

This community-based cross-sectional study was conducted from January 2009 to December 2009 in the rural field practice area of Primary Health Center (PHC), Vantamuri, Belgaum. The Vantamuri PHC has five sub-centers catering 18 villages having a total population of 31,510 . It is situated by the side of PuneBangalore National Highway and is $20 \mathrm{~km}$ from Belgaum toward north. Bhutaramanahatti sub-center was selected among the five sub-centers using random sampling technique.

\section{Sample size and technique}

As no previous studies have been recorded on agricultural workers' morbidity in this area, the prevalence was considered $50 \%$ and the sample size was calculated as 400. All agricultural workers residing in six villages, namely, Bhutaramanahatti, Desarwadi, Ukkad, Bennali, Gurlhosur, and Ghugranatti, coming under Bhutaramanahatti sub-center of PHC Vantamuri, Belgaum, were listed. By four-digit random number table method, 400 participants were selected.

\section{Selection criteria}

Agricultural workers residing in the study area for at least 1 year preceding the date of survey, aged between 16 years and 60 years, were included in the study. Migrants, pregnant and lactating women working as agricultural workers were excluded from the study.

\section{Procedure}

The study was approved by Institutional Ethics Committee for Human Subjects' Research, Jawaharlal Nehru Medical College, Belgaum. The study participants were interviewed in their households/fields. Based on the selection criteria, the study participants were selected, and written informed consent was obtained from all the participants. The data were collected using predesigned and pretested proforma. Data regarding demographic variables like place of residence, age, sex, education status, marital status, socioeconomic status, and type of family were recorded. The personal history was taken for diet, sleep pattern, appetite, and personal habits.

\section{Study variables}

Self-reported illness symptoms experienced by the subjects (1 month preceding the survey) were enquired and noted. The study participants were also interviewed for their health-seeking behaviors such as priority of health care providers. Two more subsequent visits were made to collect data from those who were absent during the first visit.

\section{Statistical analysis}

The data were tabulated using MS Excel sheet and analysis was done using percentages, rates, and ratios. Chi-square test was used to find the association between attributes.

\section{RESULTS}

Among the study participants, 55.75\% were males and $44.25 \%$ were females, with a male to female ratio of 1.25:1. Equal distribution $(39 \%)$ was seen in the age group of 30-45 years and 45-60 years. There were $87(21.75 \%)$ people of age between 15 and 30 years. Majority (89.5\%) were Hindus and 10.5\% were Muslims. None belonged to Boudh, Christ, Jain, or Parsi religion. The other demographic features are as shown in Table 1.

Among the top ten morbidities, majority (62.5\%) of the study participants had morbidities associated with oral cavity, followed by musculoskeletal system $(21.75 \%)$ and respiratory system (19\%) [Figure 1]. Of the 400 agricultural workers, home remedies were sought by $67 \%$, and $33 \%$ visited a health care provider for the treatment. Overall, government doctors were opted by $48.75 \%, 28 \%$ opted private doctor, $12.25 \%$ anganwadi worker, $10 \%$ auxiliary nurse midwives, and $1 \%$ opted for pharmacist as the first priority health care provider for their illnesses. Among those cases where illness was not cured or the treatment given by the first health care provider was not satisfactory, $18.25 \%$ opted government doctor and $35.75 \%$ preferred private or AYUSH practitioners [Table 2].

In the present study, male study participants sought treatment outside more than female study participants for episode of illness [Table 3]. In the present study, significant association was found between increasing age and treatment-seeking behavior [Table 4]. No significant association was found between socioeconomic status and health-seeking behavior. 


\section{DISCUSSION}

Information on the existing disease pattern and health-seeking behavior is essential to provide need-based health care delivery to any population. India, a land of agriculture, has formed the scaffolding

\begin{tabular}{|c|c|c|}
\hline \multirow[t]{2}{*}{ Demographic characteristics } & \multicolumn{2}{|c|}{$\begin{array}{c}\text { Study } \\
\text { participants }\end{array}$} \\
\hline & No. & $\%$ \\
\hline \multicolumn{3}{|l|}{ Gender } \\
\hline Male & 223 & 55.75 \\
\hline Female & 177 & 44.25 \\
\hline \multicolumn{3}{|l|}{ Age (years) } \\
\hline $15-30$ & 87 & 21.75 \\
\hline $30-45$ & 157 & 39.25 \\
\hline $45-60$ & 156 & 39.00 \\
\hline \multicolumn{3}{|l|}{ Religion } \\
\hline Hindu & 358 & 89.50 \\
\hline Muslim & 42 & 10.50 \\
\hline \multicolumn{3}{|l|}{ Educational status } \\
\hline Illiterate & 188 & 47.00 \\
\hline $1-5$ & 152 & 38.00 \\
\hline $6-10$ & 58 & 14.50 \\
\hline$>10$ & 2 & 0.50 \\
\hline \multicolumn{3}{|c|}{ Socioeconomic status (modified B. G. Prasad's) ${ }^{*}$} \\
\hline Class III & 22 & 5.50 \\
\hline Class IV & 83 & 20.75 \\
\hline Class V & 295 & 73.75 \\
\hline \multicolumn{3}{|l|}{ Marital status } \\
\hline Single & 28 & 7.00 \\
\hline Married & 343 & 85.75 \\
\hline Widow/widower & 29 & 7.25 \\
\hline \multicolumn{3}{|l|}{ Type of family } \\
\hline Nuclear & 241 & 60.25 \\
\hline Joint & 142 & 35.50 \\
\hline Broken & 17 & 4.25 \\
\hline
\end{tabular}

\begin{tabular}{|c|c|c|c|c|c|c|c|}
\hline \multirow[t]{3}{*}{ Priority } & \multirow{3}{*}{$\begin{array}{l}\text { Treatment } \\
\text { seeking }\end{array}$} & \multicolumn{4}{|c|}{ Gender } & \multirow{2}{*}{\multicolumn{2}{|c|}{ Total }} \\
\hline & & \multicolumn{2}{|c|}{ Male } & \multicolumn{2}{|c|}{ Female } & & \\
\hline & & No. & $\%$ & No. & $\%$ & No. & $\%$ \\
\hline \multirow[t]{5}{*}{ First } & Government doctor & 126 & 31.50 & 69 & 17.25 & 195 & 48.75 \\
\hline & Private/AYUSH & 68 & 17 & 44 & 11 & 112 & 28.00 \\
\hline & Anganwadi worker & 20 & 9.00 & 29 & 16.40 & 49 & 12.25 \\
\hline & ANM & 7 & 3.10 & 30 & 18.60 & 40 & 10.00 \\
\hline & Pharmacist & 2 & 0.5 & 2 & 0.5 & 4 & 1.00 \\
\hline \multicolumn{8}{|c|}{$\chi^{2}=35.537 \mathrm{df}=4 P=0.000$} \\
\hline \multirow[t]{5}{*}{ Second } & Government doctor & 25 & 24.00 & 48 & 42.90 & 73 & 18.25 \\
\hline & Private/AYUSH & 79 & 76.00 & 64 & 57.10 & 143 & 35.75 \\
\hline & Anganwadi worker & - & - & - & - & 0 & 0.00 \\
\hline & ANM & - & - & - & - & 0 & 0.00 \\
\hline & Pharmacist & - & - & - & - & 0 & 0.00 \\
\hline
\end{tabular}

for many agro-based industries. Morbidity is more common among these industrial workers. ${ }^{[5]}$

Being a developing nation is faced with traditional public health problems like communicable diseases, malnutrition, poor

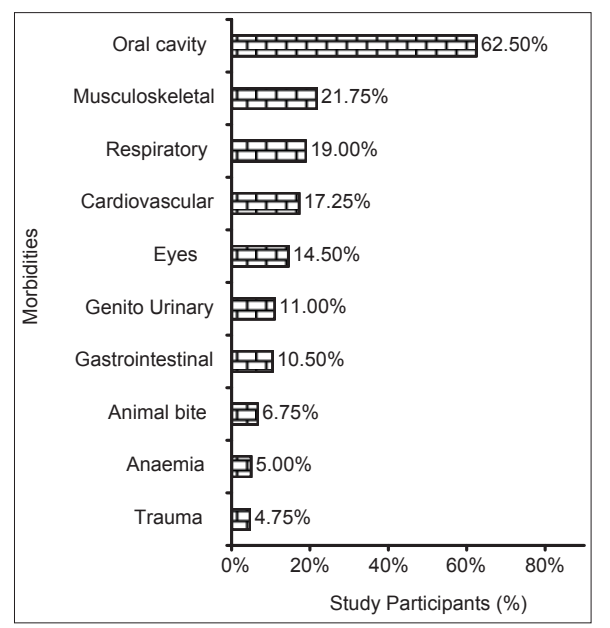

Figure 1: Distribution of study population according to top ten morbidities

\begin{tabular}{|c|c|c|c|c|}
\hline \multirow[t]{2}{*}{ Health care provider } & \multicolumn{2}{|c|}{ First priority } & \multicolumn{2}{|c|}{ Second priority } \\
\hline & No. & $\%$ & No & $\%$ \\
\hline Government doctor & 195 & 48.75 & 73 & 18.25 \\
\hline Private/AYUSH practitioner & 112 & 28.00 & 143 & 35.75 \\
\hline Anganwadi worker & 49 & 12.25 & 0 & 0 \\
\hline Auxiliary nurse midwife & 40 & 10.00 & 0 & 0 \\
\hline Pharmacist & 4 & 1.00 & 0 & 0 \\
\hline Total & 400 & 100.00 & 216 & 54.00 \\
\hline
\end{tabular}

\section{Table 4: Association of age with health-seeking}

\section{behavior}

\begin{tabular}{|c|c|c|c|c|c|c|c|c|c|}
\hline \multirow[t]{3}{*}{ Priority } & \multirow{3}{*}{$\begin{array}{l}\text { Treatment } \\
\text { seeking }\end{array}$} & \multicolumn{6}{|c|}{ Age group (in years) } & \multicolumn{2}{|c|}{ Total } \\
\hline & & \multicolumn{2}{|c|}{$15-30$} & \multicolumn{2}{|c|}{$30-45$} & \multicolumn{2}{|c|}{$45-60$} & & \\
\hline & & No. & $\%$ & No. & $\%$ & No. & $\%$ & No. & $\%$ \\
\hline \multirow[t]{5}{*}{ First } & $\begin{array}{l}\text { Government } \\
\text { doctor }\end{array}$ & 31 & 35.6 & 77 & 49.0 & 87 & 55.8 & 195 & 48.75 \\
\hline & Private/AYUSH & 25 & 28.7 & 46 & 29.3 & 41 & 26.3 & 112 & 28.00 \\
\hline & $\begin{array}{l}\text { Anganwadi } \\
\text { worker }\end{array}$ & 14 & 16.1 & 18 & 11.5 & 17 & 10.9 & 49 & 12.25 \\
\hline & ANM & 16 & 18.4 & 15 & 9.6 & 9 & 5.8 & 40 & 10.00 \\
\hline & Pharmacist & 1 & 1.1 & 1 & 0.6 & 2 & 1.3 & 4 & 1.00 \\
\hline \multicolumn{10}{|c|}{$\chi^{2}=14.360 \mathrm{df}=6 P=0.026$} \\
\hline \multirow[t]{5}{*}{ Second } & $\begin{array}{l}\text { Government } \\
\text { doctor }\end{array}$ & 25 & 46.3 & 27 & 29.7 & 21 & 29.6 & 73 & 18.25 \\
\hline & Private/AYUSH & 29 & 53.7 & 64 & 70.3 & 50 & 70.4 & 143 & 35.75 \\
\hline & $\begin{array}{l}\text { Anganwadi } \\
\text { worker }\end{array}$ & - & - & - & - & - & - & - & - \\
\hline & ANM & - & - & - & - & - & - & - & - \\
\hline & Pharmacist & - & - & - & - & - & - & - & - \\
\hline
\end{tabular}


environmental sanitation, and inadequate medical care. However, globalization and rapid industrial growth in the last few years have resulted in emergence of occupational health-related issues. Agriculture is the main occupation in India giving employment to about $58 \%$ of the people. This is in contrast to the industrialized nations like USA and Western Europe where the employment in the agricultural sector is between $4 \%$ and $12 \%{ }^{[6]}$

Agriculture, being the principle occupation in the country, exposes a considerable proportion of population to this occupation-related hazard. The major occupational diseases/ morbidity of concern in India are silicosis, musculo-skeletal injuries, coal workers' pneumoconiosis, chronic obstructive lung diseases, asbestosis, byssinosis, pesticide poisoning, and noise-induced hearing loss. ${ }^{[7]}$

India is a developing nation and presents the demographic features similar to the other developing nations of the world. Emerging occupational health problems are to be tackled along with the existing traditional public health problems like communicable diseases, malnutrition, poor environmental sanitation, and inadequate medical care. ${ }^{[7]}$ Hence, the present study was undertaken to assess the health-seeking behavior of agricultural workers.

In the present study, among the study participants, majority $(62 \%)$ suffered form morbidities associated with oral cavity, such as dental caries $(25.50 \%)$, dental stains $(21.75 \%)$, dental calculus $(11.50 \%)$, and oral sub-mucous fibrosis $(3.75 \%)$, followed by those of musculoskeletal system $(21.75 \%)$ and respiratory system (19\%).

The statistics for the overall incidence/prevalence of occupational disease and injuries for the country is not available. ${ }^{[6]}$ A study ${ }^{[8]}$ estimated an annual incidence of occupational disease between 924,700 and 1,902,300, and 121,000 deaths in India. The survey of agriculture injury incidence study ${ }^{[9]}$ in northern India estimated an annual incidence of 17 million injuries per year ( 2 million moderate to serious) and 53,000 deaths per year in agriculture alone.

A study in 2006 showed that vast majority of women farmers in mixed cropping systems suffered from intense muscular fatigue heat exhaustion and skin disorders. ${ }^{[10]}$

According to ILO, the agricultural sector is one of the most hazardous to health worldwide. Agricultural work possesses several characteristics that are risky for health: Exposure to wealth, close contact with animals and plants, extensive use of chemicals and biological products, difficult working posture, lengthy house, and use of hazardous agricultural tools and machinery. ${ }^{[11]}$

Health-seeking behavior refers to the sequence of remedial actions that individuals undertake to rectify perceived ill health. ${ }^{[7]}$ It is initiated with symptom definition, whereupon a strategy for treatment action is devised. Treatment choice involves a myriad of factors related to illness type and severity, pre-existing lay beliefs about illness causation, the range and accessibility of therapeutic options available, and their perceived efficacy, convenience, opportunity costs, quality of service, staff attitudes, as well as the age, gender, and social circumstances of the sick individual. ${ }^{[12]}$ As for health care system, in almost all the developing countries, the public and the private health sectors coexist, complementing or conflicting with each other. Yet, in health planning, least consideration is given to harmonize this coexistence in the larger benefit of the users. ${ }^{[13]}$

A number of studies have shown that trends in utilization of a health care system, public or private, formal or non-formal, by and large, vary depending on factors such as age, gender, women's autonomy, urban or rural habitat, economic status, severity of illness, availability of physical infrastructure, and type and cader of health provider. $^{[14]}$ In the developing world, medical pluralism, or the existence of several distinct therapeutic systems in a single cultural setting, is an important feature of health care. Indeed, a wide range of therapeutic choices is available, ranging from self-care to folk and western medicine, although both illness incidence and treatment options are importantly determined by poverty and gender. ${ }^{[15]}$ The type of symptoms experienced for the illness and the number of days of illness are major determinants of health-seeking behavior and choice of care provider. In case of a mild single symptom such as fever, home remedies or folk prescriptions are used, whereas with multiple symptoms and longer period of illness, biomedical health provider is more likely to be consulted. ${ }^{[16]}$

In the present study, 67\% took home remedies and 33\% visited health care provider. Overall, $48.75 \%$ opted for government doctor, $28 \%$ private doctor, $12.25 \%$ anganwadi worker, $10 \%$ auxiliary nurse midwives, and $1 \%$ opted for pharmacist as the first priority health care provider for this illness. In 54\% cases, $18.25 \%$ opted government doctors and $35.75 \%$ preferred private or AYUSH practitioners in case illness was not cured or the treatment given by first health care provider was not satisfactory.

Traditional beliefs tend to be intertwined with peculiarities of the illness itself and a variety of circumstantial and social factors. This complexity is reflected in the health-seeking behavior, including the use of home prescriptions. The attitude of the health provider and patient satisfaction with the treatment play a role in health-seeking behavior. ${ }^{[17]}$

In a study ${ }^{[18]}$ from Bangladesh, although fever was the most reported illness, only $42.3 \%$ took service from qualified medical personnel or health facility and the highest percentage of patients went to quacks for the treatment of fever, whereas $11.8 \%$ sought no treatment at all. For treatment of gastrointestinal diseases, a higher portion of respondents took services from qualified allopathic doctors $(58.1 \%)$, although $8.1 \%$ went for self-medication. For treatment of respiratory disease, the highest portion of respondents went to qualified doctors' private chamber (31.8\%). Surprisingly, for skin/eye/ENT, none of the respondents went for self-treatment or service from medical assistants or quacks. Highest percentage of respondents took services from public health facility $(37.5 \%)$, but it is depressing that still $12.5 \%$ took treatment from kabiraj/hakims and $12.5 \%$ took no treatment at all. Overall, utilization of public health facility is not satisfactory (only 24.8\%) and a significant proportion sought services from unqualified parishioners $(28.7 \%)$. This picture was similar with the study findings in Pakistan ${ }^{[19]}$ and is still far better than the health-seeking behavior in Chakaria seen by ICDDR, B. ${ }^{[20]}$ However, our study did not analyze the data based on the symptoms reported and health-seeking behavior.

In our study, increasing age and gender were significantly associated 
with treatment-seeking behavior. In a study ${ }^{[18]}$ from Bangladesh, there was no major variation in the utilization of various sources of health care across different age groups in rural area, which was similar to the findings of other studies. ${ }^{[1,22]}$ Among the rural people, the dependence of the poorer ones is more on the quacks and better-off people rely more on the qualified private practitioners, which was consistent with other studies. ${ }^{[21,22]}$ However, one study ${ }^{[22]}$ identified sex, literacy of the household head, and disease types (aches/pain and skin/eye/ENT related illness) as the significant predictors for taking any type of formal health care. ${ }^{[15,23]}$

\section{CONCLUSION}

Agricultural workers had a multitude of health problems. Efforts to increase health-related knowledge and skills to facilitate decisions to seek appropriate health care service should be emphasized as a key component of primary health care. Further, in an increasingly pluralistic health care system, it is essential that health sector reform takes into account the full range of health providers, both private and public, and qualified and unqualified. Finally, strengthening the information, education, and communication (IEC) activities and special health check-up camps with emphasis on improvement of health and awareness could help to combat the situation.

\section{REFERENCES}

1. Ulimwengu J. Farmers' health and agricultural productivity in rural Ethiopia. AFJARE 2009;3:83-100.

2. Lal A, Pankaj S. Text book of Community Medicine - Preventive and Social Medicine. $2^{\text {nd }}$ ed, New Delhi: CBS Publishers; 2009.

3. Park K. Park's Textbook of Preventive and Social Medicine. $20^{\text {th }} \mathrm{ed}$, Jabalpur, India: Banarasidas Bhanot; 2009.

4. Lipton M, De Kadt E. Agriculture: Health linkages. Geneva: World Health Organization; 1988.

5. Prakash S, Manjunatha S, Shashikala C. Morbidity patterns among rice mill workers: A cross sectional study. Indian J Occup Environ Med 2010;14:91-3.

6. Saiyed HN, Tiwari RR. Occupational Health Research in India. Industrial Health 2004;42:141-8.

7. Christman N. The health seeking process. Cult Med Psychiat 1977;1:1357-68.

8. Leigh J, Macaskill P, Kuosma E, Mandryk J. Global burden of disease and injuries due to occupational factors. Epidemiol 1999;10:626-31.
9. Mohan D, Patel R. Design of safer agricultural equipment: Application of ergonomics and epidemiology. Int J Ind Ergonomics 1992;10:301-9.

10. Cole D. Understanding the Links between Agriculture and Health for Food, Agriculture, and the Environment. Washington, DC; International Food Policy Research Institute (IFPRI); 2006.

11. Duggal R, Amin S. Cost of Health Care: A Household Level Survey in an Indian Dstrict. Bombay: Foundation for Research in Community Health; 1989.

12. Helman C. In: Culture, health and illness. $3^{\text {rd }}$ ed. Oxford: Butterworth-Heinemann; 1995. p. 101-45.

13. Giusti D, Criel B, De Bethune X. Viewpoint: Public vs. private health care delivery: Beyond the slogans. Health Policy Plan 1997;2:193-8.

14. Shaikh BT, Hatcher J. Health seeking behaviour and health service utilization in Pakistan: Challenging the policy makers. Public Health (Oxford) 2005;27:49-4.

15. Ahmed SM, Adams AM, Chowdhury M, Bhuiya A. Gender, socioeconomic development and health-seeking behaviour in Bangladesh. Soc Sci Med 2000;51:361-71.

16. Sadiq H, Muynck AD. Health care seeking behavior of pulmonary tuberculosis patients visiting Rawalpindi. J Pak Med Assoc 2002;51:10-6.

17. Ndyomugyenyi R, Neema $S$, Magnussen $P$. The use of formal and informal services for antenatal care and malaria treatment in rural Uganda. Health Policy Plan 1998;13:94-102.

18. Rahman M, Islam MM, Islam MR, Sadhya G, Latif MA. Disease Pattern and Health Seeking Behavior in Rural Bangladesh. Faridpur Med Coll J 2011;6:32-7.

19. Mahmood N, Ali SM. The Disease Pattern and Utilization of Health Care Services in Pakistan. Pak Dev Rev2002;41:745-57.

20. Country team of the Future Health Systems Research Programme Consortium at ICDDR, B, Dhaka, Bangladesh. Vol. 1. Health Seeking Behaviour in Chakaria. Bangladesh: FHS RESEARCH brief; 2008. p. 1-4.

21. Begum S. Health Dimension of Poverty in Rural Bangladesh: Some Evidence. In: Rahman HZ, Hossain M, Sen B, editors, 1987-1994: Dynamics of Rural Poverty in Bangladesh. Dhaka: Bangladesh Institute of Development Studies; 1997.

22. Ahmed SM, Tomson G, Petzold M, Kabir ZN. Socioeconomic status overrides age and gender in determining health-seeking behaviour in rural Bangladesh. Bull World Health Organ 2005;83:109-17.

23. Ahmed SM, Adams AM, Chowdhury M, Bhuiya A. Changing health seeking behaviour in Matlab, Bangladesh: Do development interventions matter? Health Policy Plan 2003;18:306-15.

How to cite this article: Kulkarni RR, Shivaswamy MS, Mallapur MD. Health-seeking behavior of rural agricultural workers: A community-based cross-sectional study. Int J Med Public Health 2013;3:33-7.

Source of Support: Nil, Conflict of Interest: None declared. 